\title{
Author Correction: Organic field-effect optical waveguides
}

\author{
Guangyao Zhao ${ }^{1,2}$, Huanli Dong (1) ${ }^{1,3}$, Qing Liao ${ }^{3}$, Jun Jiang (1) ${ }^{4}$, Yi Luo $^{4}$, Hongbing Fu (1] ${ }^{3}$ \& Wenping Hu (1) ${ }^{1,5}$
}

Correction to: Nature Communications; https://doi.org/10.1038/s41467-018-07269-9, published online 15 November 2018

The original version of this Article contained an error in Fig. 3, in which the $x$-axes in Fig. 3e and Fig. 3f were incorrectly labelled ' $V_{d s}$ ' rather than the correct ' $V_{g s}$ '. This has been corrected in both the PDF and HTML versions of the Article.

Published online: 18 December 2018

\begin{abstract}
(c) (i)
Open Access This article is licensed under a Creative Commons Attribution 4.0 International License, which permits use, sharing, adaptation, distribution and reproduction in any medium or format, as long as you give appropriate credit to the original author(s) and the source, provide a link to the Creative Commons license, and indicate if changes were made. The images or other third party material in this article are included in the article's Creative Commons license, unless indicated otherwise in a credit line to the material. If material is not included in the article's Creative Commons license and your intended use is not permitted by statutory regulation or exceeds the permitted use, you will need to obtain permission directly from the copyright holder. To view a copy of this license, visit http://creativecommons.org/licenses/by/4.0/.
\end{abstract}

(C) The Author(s) 2018

\footnotetext{
${ }^{1}$ Beijing National Laboratory for Molecular Sciences, Key Laboratory of Organic Solids, Institute of Chemistry, Chinese Academy of Sciences, 100190 Beijing, China. ${ }^{2}$ School of Chemistry and Chemical Engineering, University of the Chinese Academy of Sciences, 100039 Beijing, China. ${ }^{3}$ Beijing Key Laboratory for Optical Materials and Photonic Devices, Department of Chemistry, Capital Normal University, 100037 Beijing, China. ${ }^{4}$ Heifei National Laboratory for Physical Sciences at the Microscale, University of Science and Technology of China, 230026 Hefei, China. ${ }^{5}$ Tianjin Key Laboratory of Molecular Optoelectronic Sciences, Department of Chemistry, School of Science, Tianjin University \& Collaborative Innovation Center of Chemical Science and Engineering, 300072 Tianjin, China. Correspondence and requests for materials should be addressed to H.D. (email: dhl522@iccas.ac.cn) or to W.H. (email: huwp@tju.edu.cn)
} 